\title{
Erratum: Neural entrainment to rhythmically-presented auditory, visual and audio-visual speech in children
}

\section{Alan J. Power*, Natasha Mead, Lisa Barnes and Usha Goswami \\ Department of Experimental Psychology, Centre for Neuroscience in Education, University of Cambridge, Cambridge, UK \\ *Correspondence: alan.j.pow@gmail.com}

Edited by:

Marcela Pena, Catholic University of Chile, Chile

Keywords: entrainment, audio-visual speech perception, rhythm, oscillations, language

\section{An erratum on}

Neural entrainment to rhythmically presented auditory, visual, and audiovisual speech in children

by Power, A. J., Mead, N., Barnes, L., and Goswami, U. (2012). Front. Psychol. 3:216. doi: 10.3389/fpsyg.2012.00216

Two inadvertent errors were discovered in Power et al. (2012). The first relates to Figure 3. This figure showed the histograms for one subject and not the whole group. A corrected Figure is included here. Rayleigh statistics carried out on these updated histograms reveal two differences in entrainment compared to the published results:

1. Theta activity at $\mathrm{Oz}$ in the visual condition, which was previously though not to be entrained, is in fact entrained.

2. Delta activity at $\mathrm{Oz}$ in the Audiovisual condition, which was previously thought to entrain to the stimulus, does not do so.

Therefore, the published data should be adjusted as follows (differing results in bold italics):

A:

$F z_{\delta}: \quad Z=16.72, \quad p<0.0001 . \quad F z_{\theta}:$ $Z=84.45, p<0.0001$

$O z_{\delta}: \quad Z=11.22, \quad p<0.0001 . \quad O z_{\theta}$ :

$Z=94.11, p<0.0001$

$\mathrm{V}:$

$F z_{\delta}: \quad Z=11.66, \quad p<0.0001 . \quad F z_{\theta}:$

$Z=2.07, p>0.05$

$O z_{\delta}: \quad Z=41.29, \quad p<0.0001 . \quad O z_{\theta}$ :

$Z=14.91, p<0.0001$
$\mathrm{AV}$ :

$F z_{\delta}: \quad Z=9.42, \quad p<0.001 . \quad F z_{\theta}$ :

$Z=92.85, p<0.0001$

$O z_{\delta}: \quad Z=2.45, \quad p>0.05 . \quad O z_{\theta}:$

$Z=90.62, p<0.0001$

The second error was observed when comparing Total Power in the A and (AV-V) conditions. ANOVA results should be as follows.

Repeated Measures ANOVA (frequency $\times$ condition) on Total Power:

- Frequency: $F_{(1,22)}=261.62, \quad p<$ $0.001, \eta p^{2}=0.922$

- Condition: $F_{(1,22)}=13.76, p=0.001$, $\eta p^{2}=0.385$

- Frequency $\times$ Condition: $F_{(1,22)}=1.42$, $p>0.05$

Neither of these results effect the overall conclusions of the paper:

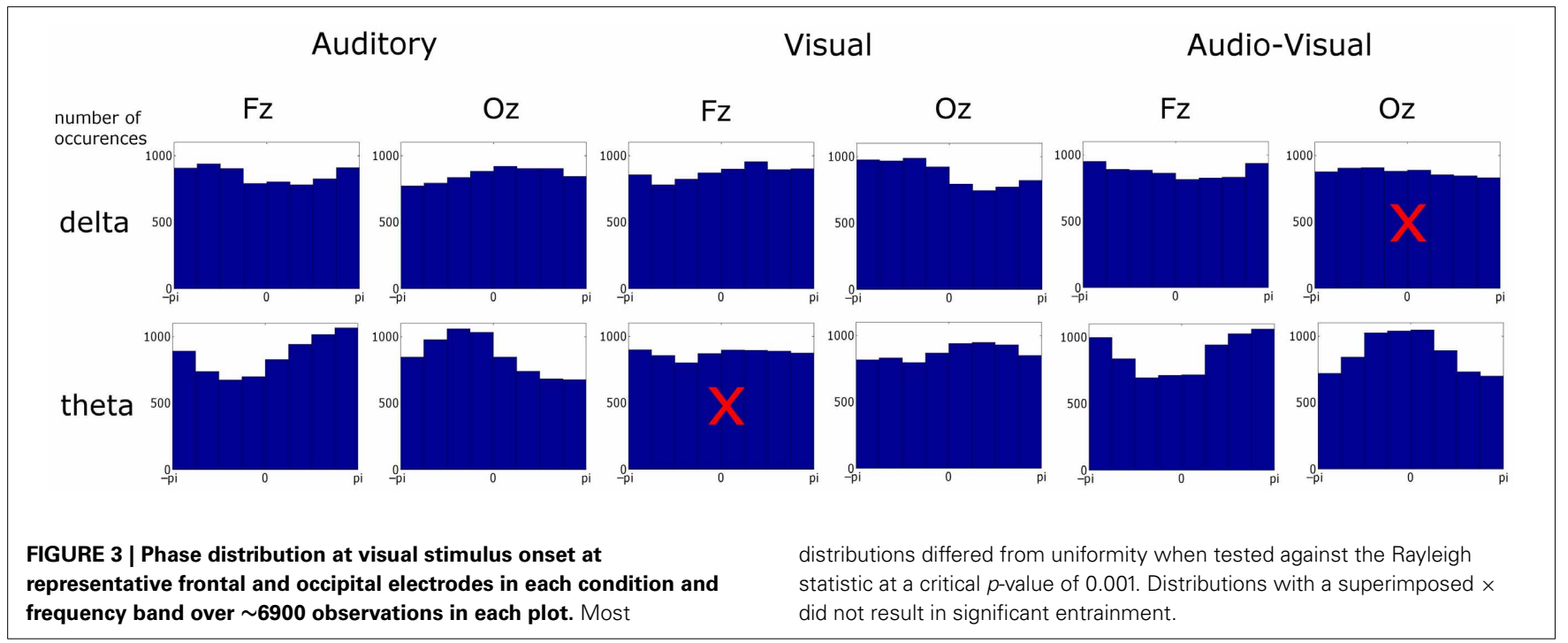


- Neural entrainment was demonstrated for all stream types, and individual differences in standardized measures of language processing were related to auditory entrainment at the theta rate.

- There was significant modulation of the preferred phase of auditory entrainment in the theta band when visual speech cues were present.

\section{REFERENCES}

Power, A. J., Mead, N., Barnes, L., and Goswami, U. (2012). Neural entrainment to rhythmically presented auditory, visual, and audio-visual speech in children. Front. Psychol. 3:216. doi: 10.3389/fpsyg.2012.00216

Received: 04 November 2013; accepted: 15 November 2013; published online: 03 December 2013.

Citation: Power AJ, Mead N, Barnes L and Goswami U

(2013) Erratum: Neural entrainment to rhythmicallypresented auditory, visual and audio-visual speech in children. Front. Psychol. 4:905. doi: 10.3389/fpsyg. 2013.00905

This article was submitted to Language Sciences, a section of the journal Frontiers in Psychology.

Copyright () 2013 Power, Mead, Barnes and Goswami. This is an open-access article distributed under the terms of the Creative Commons Attribution License (CC BY). The use, distribution or reproduction in other forums is permitted, provided the original author(s) or licensor are credited and that the original publication in this journal is cited, in accordance with accepted academic practice. No use, distribution or reproduction is permitted which does not comply with these terms. 